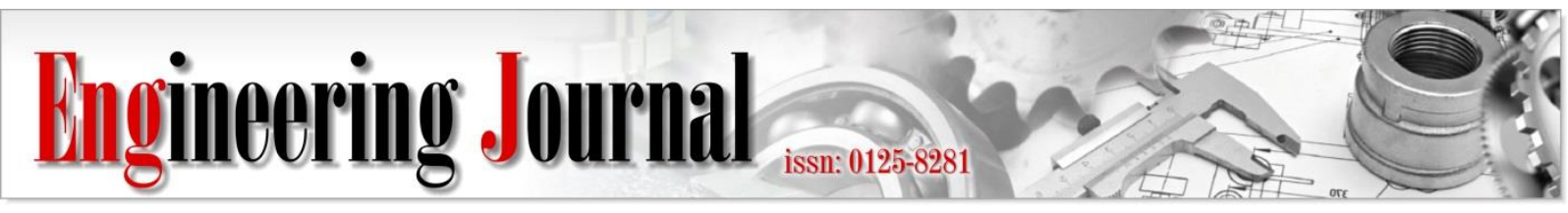

Article

\title{
Corrosion Resistance of Ti-6Al-4V Machined Surfaces Improved by Thermal Oxidation
}

\author{
Carolina Aurélia Ribeiro Maestro ${ }^{\mathrm{a}}$, Marina Cristina Ferreira ${ }^{\mathrm{b}}$, \\ Alysson Helton Santos Bueno ${ }^{c}$, and Artur Mariano de Sousa Malafaia ${ }^{\mathrm{d}, *}$
}

São João Del Rei Federal University (UFSJ), Campus Santo Antônio, Praça Frei Orlando, 170, Centro, 36307-352, São João Del Rei/MG, Brazil

E-mail: acarolinarmaestro@gmail.com, bferreira-marina@outlook.com, calyssonbueno@ufsj.edu.br, darturmalafaia@ufsj.edu.br (Corresponding author)

\begin{abstract}
Ti-6A-14V alloy is widely used in implants and prosthesis applications. Although machining is a fast and economical process, the roughness generated can compromise corrosion resistance. Thus, the goal of this study was to overcome this limitation using thermal oxidation in machined surfaces. Samples with polished surfaces were used for comparison purposes. Two sets of machining parameters were used to generate different roughness, property evaluated in polished and machined samples before and after thermal oxidation. Vickers microhardness and polarization tests using simulated body fluid (SBF) were also performed. Thermal oxidation generated similar microhardness for polished and machined samples, higher than for polished and non-oxidized condition. On the other hand, oxidation increased the roughness only for polished condition. The corrosion resistance was improved in all oxidized samples, and the best result was found to the intermediate roughness $(\mathrm{Ra}=0.76 \mu \mathrm{m})$, in a machined sample. The results demonstrated that thermal oxidation can be used to overcome machining limitations regarding corrosion resistance, achieving behavior even better than polished samples.
\end{abstract}

Keywords: Thermal oxidation, machining, Ti- $6 \mathrm{Al}-4 \mathrm{~V}$, roughness, corrosion resistance, biomaterial.

ENGINEERING JOURNAL Volume 24 Issue 5

Received 13 March 2020

Accepted 30 July 2020

Published 30 September 2020

Online at https://engj.org/

DOI:10.4186/ej.2020.24.5.185 


\section{Introduction}

Titanium and its alloys are widely used in the aerospace, chemical, automotive and biomedical industries. This is possible due to its excellent chemical and mechanical properties, such as its low density, high mechanical resistance, formability and machinability, low chemical reactivity, excellent resistance to corrosion and biocompatibility. Regarding biomedical application, titanium is present in orthopedic and orthodontic components, with Ti-6Al-4V being one of the most used $\alpha+\beta$ alloys currently [1-4], including developments in new manufacture techniques using laser to achieve structured components and promoting better mechanical properties [5-7].

Pure titanium is an element that has allotropy, and may have a compact hexagonal structure, called $\alpha$ phase, or a body-centered cubic structure called $\beta$, depending on the temperature to which it is exposed. The $\alpha$ phase is stable at room temperature, while the $\beta$ phase is stable at temperatures above $882{ }^{\circ} \mathrm{C}$. Therefore, some alloying elements are added with the intention of favoring the formation of one phase, or even both phases, at room temperature. In the case of the Ti-6Al-4V alloy, aluminum acts to stabilize the $\alpha$ phase and vanadium stabilizes the $\beta$ phase, allowing the existence of an alpha + beta alloy [8]. Alloys of this nature have better properties when compared to alloys containing only one of the phases, presenting a combination of the best properties of each of these phases. For example, an $\alpha+\beta$ titanium alloy with aluminum in its composition has a lower density than pure titanium or a beta titanium alloy. This occurs as the specific mass of aluminum is almost half of the specific mass of titanium. In addition, $\alpha+\beta$ alloys have good resistance to corrosion, fatigue and fracture [9].

Regarding biomedical demands, one must be aware of the requirements that will be imposed on the implanted material to an adequate selection. The superficial morphology of the implanted material is directly related to cell integration and the non-rejection of the material in the post-implantation period [10]. Adequate cell growth around the implant, as well as the absence of inflammation caused by the release of ions in the body, are directly related to the physical-chemical properties of the material's surface, being hardness, roughness and corrosion resistance in fluids the most important. Thus, several techniques of superficial modification have been used in order to guarantee the success of the implant $[1,11-13]$, as they have an important impact in the human tissue's response $[14,15]$.

These surface modification techniques can have a chemical, physical or mechanical character [11]. The physical technique most widely used is thermal oxidation. This is because it is a technique of simple execution and low cost, which creates a stable and adherent ceramic oxide film composed mainly by $\mathrm{TiO}_{2}$ (rutile), and promotes the improvement of the corrosion, wear and biocompatibility properties of the material [16-22]. The temperature and time range suitable for thermal oxidation in Ti-6Al-4V alloy was investigated by Kumar et al. [16] who evaluated temperatures between 500 and $800{ }^{\circ} \mathrm{C}$, in periods between 8 and 48 hours, aiming to increase the corrosion resistance in simulated body fluid. Through electrochemical tests they determined the treatment at $650{ }^{\circ} \mathrm{C}$, for $24 \mathrm{~h}$ as the most appropriate. In a previous study [17], our group demonstrated that thermal cycles could be an alternative to isothermal oxidation, suggesting control of roughness surface and better corrosion resistance in Ti-6Al-4V, oxidized at $650{ }^{\circ} \mathrm{C}$. For the same alloy, Wang et al. [18] demonstrated improvement in biotribological and corrosion behavior after thermal oxidation at $700{ }^{\circ} \mathrm{C}$. Mohammed [19] oxidized Ti-15Zr$12 \mathrm{Nb}$ at 450,650 and $850{ }^{\circ} \mathrm{C}$, observing increase in roughness, microhardness and wear resistance, due to a high-quality oxide layer formed.

The biocompatibility of thermally oxidized titanium was also investigated, showing interesting results. Wen et al. [20] observed high wear resistance and higher cell adhesion in Ti-6Al-4V oxidized at $700{ }^{\circ} \mathrm{C}$. García-Alonso et al. [21], testing the same alloy observed similar behavior between non oxidized and thermal oxidized at 500 and $700{ }^{\circ} \mathrm{C}$ regarding biocompatibility, with better cell attachment for the higher temperature. Finally, Saldaña et al. [22] demonstrated that Ti-6Al-4V oxidized at 500 and $700^{\circ} \mathrm{C}$ decreased the $\mathrm{Ti}$ and $\mathrm{Al}$ ion release in a cell culture medium, improving the biocompatibility, as higher levels of Ti ion release can generate poor cell proliferation and differentiation, while $\mathrm{Al}$ ion release was related to neural diseases. Finally, due to the rutile properties, it was also employed on stainless steel as coating, improving biocompatibility characteristics [23].

In relation to surface mechanical changes, machining is a technique that can be used due to the good machinability of titanium and its alloys and the possibility of obtaining a surface with a relatively low roughness value by this process. A less rough surface finish is important for bio applications, as it guarantees less surface friction, thus reducing the corrosive process [11, 24]. A study conducted by Ribeiro Filho et al. [24] evaluated the resistance to corrosion, in simulated body fluid, of the Ti$6 \mathrm{Al}-4 \mathrm{~V}$ alloy with different surface roughness generated by different machining parameters, demonstrating by the statistical method of response surface that an optimum surface roughness value $\mathrm{Ra}$ would be $0.768 \mu \mathrm{m}$ and that with this value it would be possible to obtain a corrosion current density $18.8 \%$ lower than for the values obtained in the studied surface roughness range (values greater than that determined).

Thus, although machining is a practical and efficient method of shaping titanium parts and implants, the roughness left by the process can limit the corrosion resistance of these materials. For comparison, all the researches cited here, related to thermal oxidation [16-22], performed the treatment in polished samples, to guarantee a low roughness. Therefore, the objective of this study is to generate surface roughness values close to the optimum value found by Ribeiro Filho et al., [24] through machining of the Ti-6Al-4V alloy and later use the thermal oxidation 
technique on the obtained surfaces, aiming to obtain better properties for its use as biomaterial as well as to evaluate the corrosion resistance of the samples in simulated body fluid, comparing to polished and polished and oxidized samples.

\section{Materials and Methods}

Figure 1 summarizes the methodology steps that will be fully described in the following subsections.
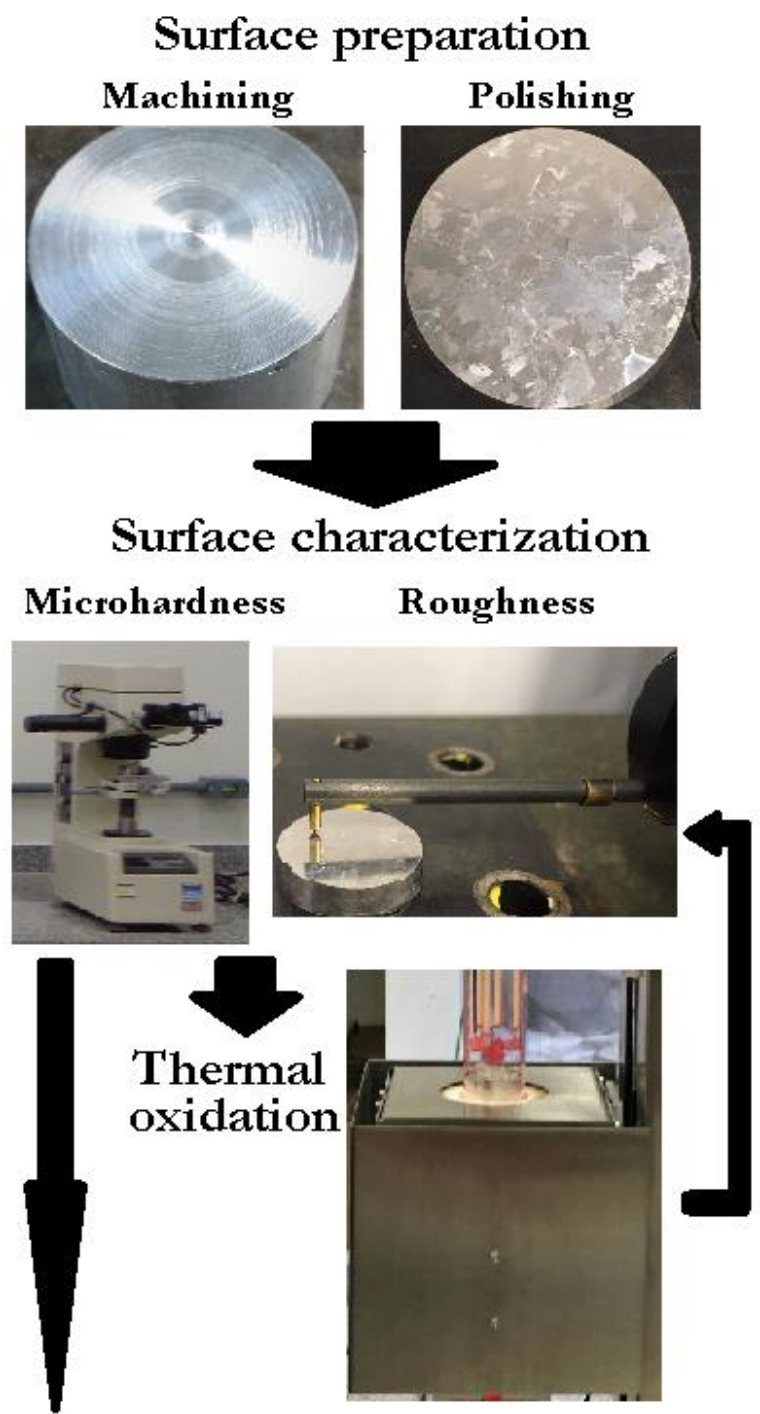

\section{Corrosion tests}

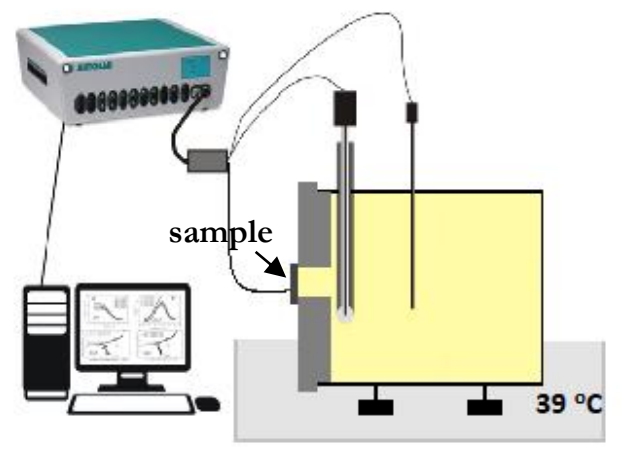

Fig. 1. Methodology flowchart scheme detailing the main procedures employed in the present study.

\subsection{Sample Preparation}

Ti-6Al-4V samples were extracted from a cylindrical bar with approximately $17.25 \mathrm{~mm}$ in diameter. The samples were cut slowly and with plenty of refrigerant fluid to avoid the material heating. For EDS analysis a sample was mounted in resin and then sanded with silicon carbide sandpaper until 1200 grit, polished with $1 \mu \mathrm{m}$ alumina suspension and chemically attacked with Kroll reagent $\left(100 \mathrm{ml} \mathrm{H}_{2} \mathrm{O}, 5 \mathrm{ml} \mathrm{HNO}_{3}\right.$ and $\left.3 \mathrm{ml} \mathrm{HF}\right)$. Prior to thermal oxidation, the samples were chemically attacked to remove any type of impurity from the surface as also the native passive oxide layer. For the attack the samples were immersed for approximately 60 seconds in a solution at $40{ }^{\circ} \mathrm{C}$, composed of 35 vol. $\% \mathrm{HNO}_{3}, 5 \mathrm{vol} . \% \mathrm{HF}$ and distilled water.

Regarding surface finishing, the samples were sanded (until 1200 grit SiC paper) and polished (1 $\mu \mathrm{m}$ alumina suspension) as reference. For samples that have been oxidized, besides the surface polishing finishes already presented in previous study [17], two sets of machining parameters were chosen in order to produce surfaces with roughness close to the optimum point found by Ribeiro Filho et al. [24], where Ra assumed a value of $0.768 \mu \mathrm{m}$. Due to the fact that the samples studied by them [24] have been turned and the samples of this study have been produced by a bar cutting and later faceted, the machining parameters adopted in that study (depth of cut, cutting speed, feed and rotation) could not be used. Thus, the required roughness was found through attempts. After finding the parameters set for Roughness 1 (around 0.768 $\mu \mathrm{m})$, the rotation, depth and cutting speed were kept constant and the feed rate was increased to generate a higher roughness finishing. The samples were faceted on a conventional ROMI lathe using the CNMG 120408 cutting insert. The machining parameters used are shown in Table 1.

Table 1. Machining parameters used to prepare samples surface.

\begin{tabular}{|c|c|c|c|c|}
\hline Condition & $\begin{array}{c}\text { Cutting } \\
\text { Depth } \\
\text { (mm) }\end{array}$ & $\begin{array}{l}\text { Feed } \\
\left(\frac{\mathrm{mm}}{\min }\right)\end{array}$ & $\begin{array}{l}\text { Rotation } \\
\text { (rpm) }\end{array}$ & $\begin{array}{c}\text { Cutting } \\
\text { Speed } \\
\left(\frac{\mathrm{m}}{\mathrm{min}}\right)\end{array}$ \\
\hline Roughness 1 & 0.2 & 0.119 & 1050 & 66 \\
\hline Roughness 2 & 0.2 & 0.166 & 1050 & 66 \\
\hline
\end{tabular}

\subsection{Surface Oxidation}

The isothermal oxidation treatments were carried out in samples polished and machined at $650{ }^{\circ} \mathrm{C}$ for 24 hours, followed by cooling inside the oven, to avoid high thermal stresses. These thermal oxidation parameters were chosen because they provided the best corrosion resistance for $\mathrm{Ti}$ 6Al-4V alloy, according to Kumar et al. [16], in a study where thermal oxidation treatments were carried out with different durations and temperatures, and were also the parameters used in our previous research [17], comparing isothermal and cyclic oxidation treatments. 


\subsection{Roughness and Microhardness Measurements}

Vickers microhardness was determined for thermally oxidized samples with all surface finish conditions and for polished and non-oxidized samples. The measurements were performed using a microdurometer Mitutoyo model MVK G1 with a pyramidal indenter with a square base, applying a load of $0.2 \mathrm{~kg}$ for 20 seconds. Five measurements were made in each sample for all conditions, then the mean and standard deviation were calculated.

$\mathrm{Ra}$ roughness was also evaluated on the surface of machined samples oxidized and not thermally oxidized using a Taylor Hobson ${ }^{\circledR}$ profilometer model Form Talysurf Intra. The measurements were performed with a cutoff of $80 \mu \mathrm{m}$ and a length of $5 \mathrm{~mm}$. For all samples, five measurements were taken to determine the mean and standard deviation.

\subsection{Corrosion Polarization Tests}

Electrochemical polarization tests were performed using a flat cell in an Autolab Multi Potentiostat model PGSTAT101, platinum counter electrode, saturated calomel reference electrode and simulated body fluid (SBF) as solution with scan speed of $0.33 \mathrm{mV} / \mathrm{s}$. The SBF solution was prepared according to the instructions present in Kokubo's study [25], and Table 2 presents the components as well as the quantity and order of addition in the solution. Two polarization curves were obtained for each condition evaluated and the best curve for each condition was used to be presented in the results.

Table 2. Components, their amounts and the addition sequence to prepare $1000 \mathrm{ml}$ of simulated body fluid (adapted from [25]).

\begin{tabular}{lcc}
\hline Order & Reagents & Amount \\
\hline 1 & $\mathrm{NaCl}$ & $8.035 \mathrm{~g}$ \\
2 & $\mathrm{NaHCO}_{3}$ & $0.355 \mathrm{~g}$ \\
3 & $\mathrm{KCl}$ & $0.225 \mathrm{~g}$ \\
4 & $\mathrm{~K}_{2} \mathrm{HPO}_{4} \cdot 3 \mathrm{H}_{2} \mathrm{O}$ & $0.231 \mathrm{~g}$ \\
5 & $\mathrm{MgCl}_{2} \cdot 6 \mathrm{H}_{2} \mathrm{O}$ & $0.311 \mathrm{~g}$ \\
6 & $1.0_{\mathrm{M}}-\mathrm{HCl}$ & $39 \mathrm{ml}$ \\
7 & $\mathrm{CaCl}_{2}$ & $0.292 \mathrm{~g}$ \\
8 & $\mathrm{Na}_{2} \mathrm{SO}_{4}$ & $0.072 \mathrm{~g}$ \\
9 & $\mathrm{Tris}$ & $6.118 \mathrm{~g}$ \\
10 & $1.0_{\mathrm{M}}-\mathrm{HCl}$ & $0-5 \mathrm{ml}$ \\
\hline
\end{tabular}

During the polarization tests, the sample was outside the cell, as shown in Fig. 1 and was exposed to the solution contained in the cell through a side hole with an area of approximately $1 \mathrm{~cm}^{2}$, containing a rubber ring. Chamfers were made on the edges of the samples to fix the potentiostatic cables directly on them. The SBF solution was maintained at $39{ }^{\circ} \mathrm{C}$ to simulate an extreme temperature situation in the human body. During the polarization test, the open circuit potential (OCP) was determined over $1 \mathrm{~h}$, followed by a scan to $2 \mathrm{~V}$ above the
OCP at a rate of $0.5 \mathrm{mV} / \mathrm{s}$. The option for using only the anodic branch was based on previous studies in titanium alloys, focusing on evaluate the degradation of the oxidized film [17, 24, 26, 27].

\section{Results and Discussion}

\subsection{Microstructural Characterization}

The evaluation of the microstructure and chemical composition of the alloy was carried out by means of scanning electron microscopy and EDS analyses, as presented in previous study [17]. Figure 2 shows a micrograph of the material's microstructure together with its chemical composition. The alpha phase represents the matrix of the material while the beta phase is in the form of dark lamellae. This differentiation can be clearly seen in the image. The analysis of the chemical composition of the alloy showed that although the amount of aluminum was within the range recommended by ASTM F136, the amount of vanadium was below the minimum required (3.5\%). However, the study was carried out using this alloy since it had already been used in a previous study [17] with similar purposes. Furthermore, the vanadium does not take important role in the thermal oxidation of Ti- $6 \mathrm{Al}-4 \mathrm{~V}$ alloy between 500 and $800{ }^{\circ} \mathrm{C}$, where $\mathrm{TiO}_{2}$ was the main oxide reported in previous studies, with minor $\mathrm{Al}_{2} \mathrm{O}_{3}$ formation in some cases, and never presenting vanadium oxides [16, 18, 21, 28]. Thus, as the analysis and characterizations performed here are strictly related to the surface oxide layer, this lower vanadium content was considered acceptable.

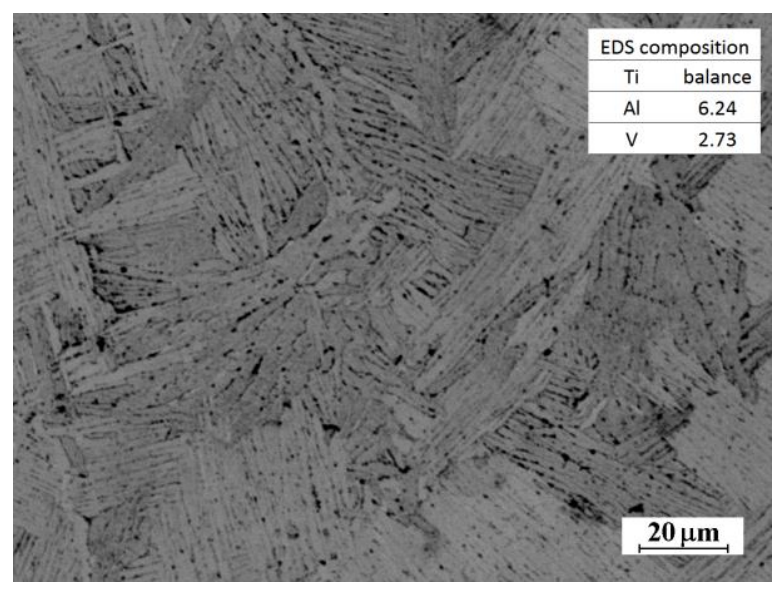

Fig. 2. Alloy microstructure observed by SEM and EDS analysis before heat treatments. (Taken from ref [17])

\subsection{Roughness}

The averages of $\mathrm{Ra}$ roughness measurements found after the machining and polishing processes, in the conditions before and after thermal oxidation, are shown in Fig. 3a. The presented values configure the general average of the values and the deviation for the samples in each condition. The polished sample showed a higher increase in roughness after oxidation. Since the growth of 
the oxide occurs irregularly, this increase in roughness is due to the roughness presented by the oxide layer. According to the literature, the roughness of titanium oxide is proportionally related to the grain size of the material and both are directly related to the increase in temperature to which the material is exposed [29]. For machined samples, the thermal oxidation did not modify significantly the roughness, considering the deviation bars. As can be seen in Fig. 3b, the roughness profile measured, for a sample machined (Roughness 2) and oxidized, clearly follows the machining profile. After machining, a spiral profile left by the tool during turning is observed. In this way, the roughness measured radially in the sample passes by peaks and valleys left by the machining tool. Thus, after oxidation, the roughness variation was practically null, since the oxide was formed homogeneously in the peaks and valleys of the profile.
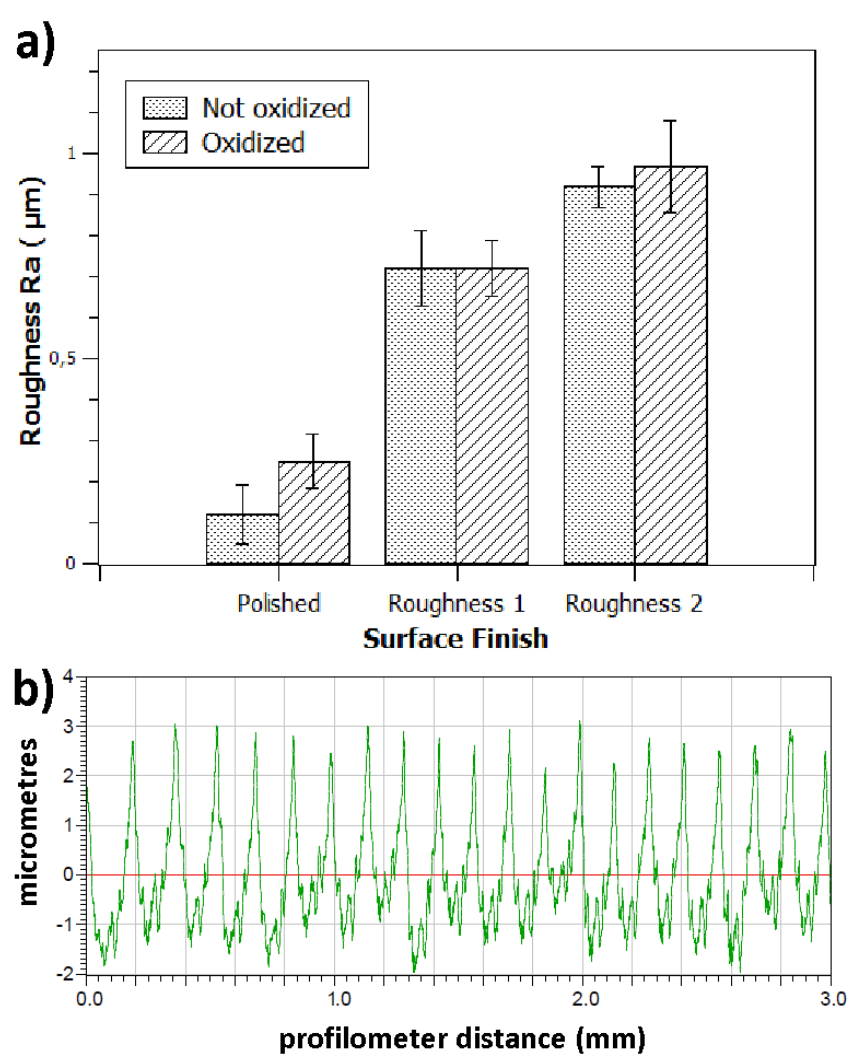

Fig. 3. Roughness analysis: a) $\mathrm{Ra}$ measurements for polished and machined samples before and after thermal oxidation and b) roughness profile observed for a machined and oxidized sample.

\subsection{Microhardness}

The increase in the microhardness is considered an important characteristic for biomaterials, especially for those that will constitute joint region implants, since these materials are subject to constant friction and this property can help prevent wear [26]. Figure 4 shows the microhardness values for the thermal oxidized and nonheat-treated polished samples. After thermal oxidation, there was a large increase in microhardness for all surface finish conditions. Considering the standard deviation, which showed similar values after five measurements, for all samples, it can be seen that, after heat treatment, all samples showed the same level of surface microhardness, approximately $80 \%$ higher than the polished sample. This suggests similarity in the formed oxides, both in relation to morphology and in relation to the composition and demonstrates that the different roughness profiles did not influence the microhardness. In a previous study of our group, it was demonstrated by X-ray diffraction that the polished and oxidized sample had the formation of rutile [17], which must have occurred for all the oxidized samples in the present study, since the material and parameters of thermal oxidation were the same.

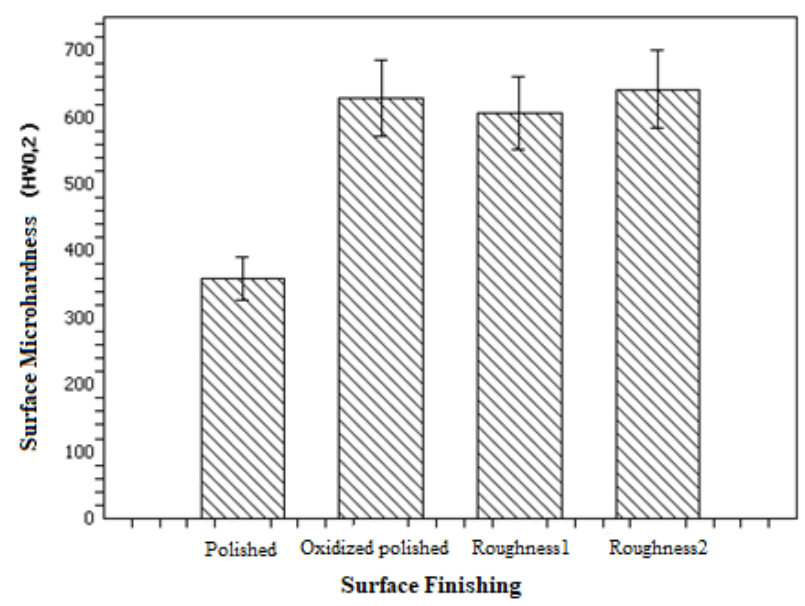

Fig. 4. Surface microhardness determined for polished, oxidized polished, roughness 1 and roughness 2 oxidized samples.

\subsection{Polarization}

Right after being implanted in the organism, the material is exposed to extracellular body fluids. Amino acids, proteins and the concentration of chloride ions in these fluids are able to corrode the material [1, 30]. Although titanium and its alloys have high resistance to corrosion when implanted, studies have reported the accumulation of titanium ions in tissues adjacent to the implant, suggesting the occurrence of corrosion of the material [1]. However, using thermal oxidation treatments it is possible to increase the corrosion resistance of titanium and its alloys [16, 17, 26].

To check the efficacy of thermal oxidation the material had its corrosion resistance in SBF assessed by polarization tests. Figure 5 presents the best polarization curves for each condition and it can be seen that up to approximately 1000 millivolts, all samples showed a passive region, which shows that the oxide film, from the heat treatment, had a protective character and considerably increased the corrosion resistance of the samples. After 1000 millivolts, the current density for the heat-treated samples started to increase while the current density of the untreated sample remained constant. The behavior of the curves for the three treated samples was 
similar, and for a current density of 1000 millivolts, the polished sample and the sample with Roughness 2 showed practically the same resistance to corrosion, while the sample with Roughness 1 showed a corrosion resistance superior to the others. In contrast, the untreated sample kept the film passive for larger potentials. This is probably since the passive film, naturally formed on the alloy surface, has fewer defects than the oxide film formed during heat treatment. Furthermore, in our previous evaluations [17] it was demonstrated that some pits were formed by differential aeration near the O-ring region. However, in real clinical application realities [16], there are no situations where high potentials are applied, thus, for the evaluated purpose, the treated samples showed a considerable improvement in corrosion resistance, as discussed in previous study [17].

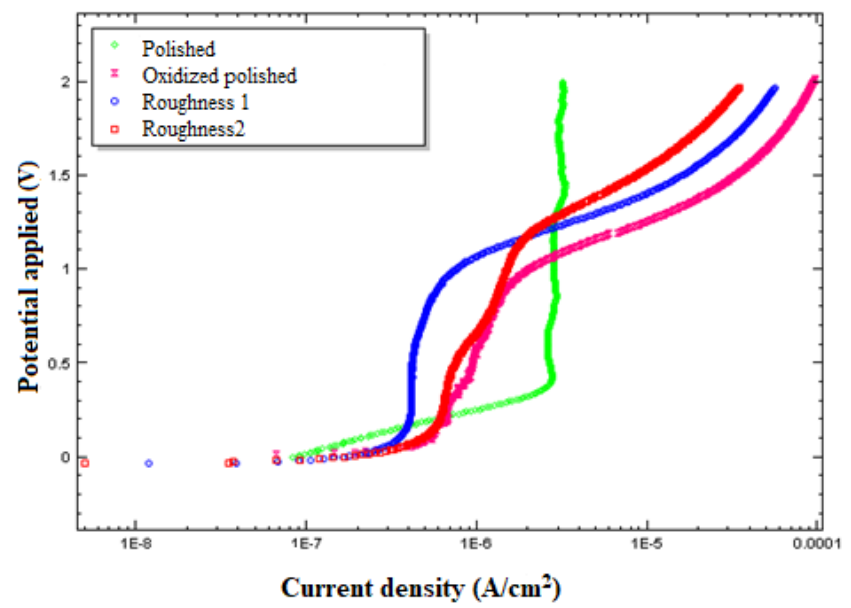

Fig. 5. Polarization results for untreated and heat-treated samples using SBF solution.

When evaluating the influence of surface roughness on the corrosion resistance of oxidized samples, it is possible to observe that within the studied range, both for low values of $\mathrm{Ra}(0.24 \mu \mathrm{m})$ and higher values $(0.92 \mu \mathrm{m})$, there is a tendency of less resistance to corrosion when compared to intermediate roughness $(0.76 \mu \mathrm{m})$, although similar for both values. This result demonstrates that thermal oxidation can improve the corrosion resistance properties of Ti-6Al-4V alloy for samples with high roughness after machining, a factor mentioned as a limitation previously [24]. In addition, the best result found here was observed for the intermediate roughness tested, after machining and oxidation, overcoming the polished and oxidized condition. Despite a previous study by our group [17], evaluating thermal cycles to show that in the $\mathrm{Ra}$ range between 0.17 and $0.35 \mu \mathrm{m}$, the lowest value generated the best corrosion resistance, in the present study, the Ra roughness of $0.76 \mu \mathrm{m}$ presented the best result. These results demonstrate that the thermal oxidation of machined surfaces can generate a higher resistance to corrosion of the Ti-6Al-4V alloy in SBF.

Table 3 shows the current average values 500 millivolts above the OCP for all samples. Once again, all heat-treated samples, regardless of the initial surface roughness, have greater resistance to corrosion than the untreated sample, with emphasis on the results presented by the curve of the sample with Roughness 1 . Through the measured values of current density at open circuit potential (OCP) shown in Table 3, there was a decrease for the heat-treated samples. This suggests that the oxide film from heat treatments is more protective than the oxide film naturally formed on the material's surface, which causes substrate corrosion in the electrolyte. This improvement in corrosion resistance by the formation of a protective oxide film, by thermal oxidation has already been presented in the literature by several authors, among them Kumar et al. [16], who showed an increase in corrosion resistance in simulated body fluid, for the Ti$6 \mathrm{Al}-4 \mathrm{~V}$ alloy after several isothermal oxidation routes. Although thermal oxidation is known to improve corrosion resistance in titanium alloys, the present research demonstrated that it can be used in surfaces with higher roughness obtained by machining.

Table 3. Corrosion tests data: values of polarization tests: open-circuit potential and density current $500 \mathrm{mV}$ above OCP (I $500 \mathrm{mV}$ ).

\begin{tabular}{lcc}
\hline $\begin{array}{l}\text { Sample } \\
\text { Condition }\end{array}$ & OCP, $\mathbf{~ m V}$ & $\begin{array}{c}\text { I } \mathbf{5 0 0} \mathbf{~ m V}, \\
\mathbf{A} / \mathbf{c m}^{2}\end{array}$ \\
\hline Polished & -7.92 & $2.7 \times 10^{-6}$ \\
Oxidized Polished & 9.77 & $9.5 \times 10^{-7}$ \\
Roughness 1 & -36.01 & $4.2 \times 10^{-7}$ \\
Roughness 2 & -35.24 & $7.5 \times 10^{-7}$ \\
\hline
\end{tabular}

\section{Conclusions}

Samples of Ti-6Al-4V with different initial roughness, obtained by machining (two sets of different parameters) or polishing, were oxidized isothermally at $650{ }^{\circ} \mathrm{C}$ for 24 hours. The main findings of the study are summarized below:

- All oxidized samples were compared with a polished sample, showing improvement in corrosion resistance and increased microhardness, due to the formation of an oxide layer.

- The surface roughness was evaluated, before and after oxidation, demonstrating that the heat treatment significantly increases the roughness of polished samples, from $\mathrm{Ra}=0.12 \pm 0.071 \mu \mathrm{m}$ to $0.25 \pm 0.067 \mu \mathrm{m}$, but practically did not change for the machined samples, which were initially already higher, $\mathrm{Ra}=0.76 \mu \mathrm{m}$ or $0.92 \mu \mathrm{m}$ depending on machining parameters.

- The oxidized sample with intermediate roughness $(\mathrm{Ra}=0.76 \mu \mathrm{m})$ showed better results than the others in terms of corrosion resistance. This suggests that surface roughness is directly related to corrosion resistance, not only for samples 
without heat treatment, as had already been demonstrated in the literature, but also for heattreated samples.

- Finally, it is concluded that thermal oxidation can provide corrosion resistance even for surfaces with high initial roughness, which overcomes the limitation presented by machined surfaces, demonstrating the possibility of using these techniques together for the surface finish of orthopedic and orthodontic implants.

\section{Acknowledgement}

The authors would like to acknowledge FAPEMIG Minas Gerais State Agency for Research and Development for the undergraduate research scholarship.

\section{References}

[1] X. Liu, P. K. Chu, and C. Ding, "Surface modification of titanium, titanium alloys, and related materials for biomedical applications," Mater. Sci. Eng. R Reports, vol. 47, no. 3-4, pp. 49-121, 2004.

[2] S. Nag, R. Banerjee, and H. L. Fraser, "Microstructural evolution and strengthening mechanisms in Ti-Nb-Zr-Ta, Ti-Mo-Zr-Fe and Ti15Mo biocompatible alloys," Mater. Sci. Eng. C, vol. 25, no. 3, pp. 357-362, 2005.

[3] M. T. Mohammed, Z. A. Khan, and A. N. Siddiquee, "Beta titanium alloys: The lowest elastic modulus for biomedical applications: A review," Int. J. Chem. Mol. Nucl. Mater. Metall. Eng., vol. 8, p 821-827, 2014.

[4] M. Geetha, A. K. Singh, R. Asokamani, and A. K. "Gogia, Ti based biomaterials, the ultimate choice for orthopaedic implants-A review," Prog. Mater Sci., vol. 54, pp. 397-425, 2009.

[5] R. Wauthle, B. Vrancken, B. Beynaerts, K. Jorissen, J. Schrooten, J. P. Kruth, J. Van Humbeeck, "Effects of build orientation and heat treatment on the microstructure and mechanical properties of selective laser melted Ti6Al4V lattice structures," Addit. Manuf., vol. 5, pp. 77-84, 2015.

[6] A. Antolak-Dudka, P. Płatek, T. Durejko, P. Baranowski, J. Małachowski, M. Sarzyński, and T. Czujko, "Static and dynamic loading behavior of Ti6Al4V honeycomb structures manufactured by Laser Engineered Net Shaping (LENSTM) technology," Materials (Basel), vol. 12, pp. 1-20, 2019.

[7] A. Szafrańska, A. Antolak-Dudka, P. Baranowski, P. Bogusz, D. Zasada, J. Małachowski, and T. Czujko, "Identification of mechanical properties for titanium alloy Ti-6Al-4V produced using LENS technology," Materials (Basel), vol. 16, pp. 1-19, 2019.

[8] M. J. Donachie, "Understanding the metallurgy of titanium," in Titanium: A Technical Guide, 2nd ed. Ohio: ASM International, 2000, ch. 3, sec. 2, pp. 13 24.
[9] M. Peters, J. Hemptenmacher, J. Kumpfert, and C. Leyens, "Structure and properties of titanium and titanium alloys," in Titanium and Titanium Alloys: Fundamentals and Applications, 1st ed. Weinheim, Germany: Wiley-VCH, 2003, ch. 1, sec. 1.10, pp. 1-35.

[10] Q. Chen and G. A. Thouas, "Metallic implant biomaterials," Mater. Sci. Eng. R, vol. 87, pp. 1-57, 2015.

[11] S. Izman et al., "Surface modification techniques for biomedical grade of titanium alloys: Oxidation, carburization and ion implantation processes," in Titanium Alloys - Towards Achieving Enhanced Properties for Diversified Applications, 1st ed. London, UK, 2012, ch. 9, pp. 201-228.

[12] K. Aniołek, M. Kupka, A. Barylski, and G. Dercz, "Mechanical and tribological properties of oxide layers obtained on titanium in the thermal oxidation process," Appl. Surf. Sci., vol. 357, pp. 1419-1426, 2015.

[13] Y. Oshida, "Prologue," in Bioscience and Bioengineering of Titanium Materials. Oxford, UK: Elsevier, 2007, pp. xiii-xiv.

[14] B. D. Boyan, T. W. Hummert, D. D. Dean, and Z. Schwartz, "Role of material surfaces in regulating bone and cartilage cell response," Biomaterials, vol. 17, pp. 137-146, 1996.

[15] B. Chehroudi, D. McDonnell, and D. M. Brunette, "The effects of micromachined surfaces on formation of bonelike tissue on subcutaneous implants as assessed by radiography and computer image processing," J. Biomed. Mater. Res., vol. 34, pp. 279-290, 1998.

[16] S. Kumar, T. S. N. Sankara Narayanan, S. Ganesh Sundara Raman, and S. K. Seshadri, "Thermal oxidation of Ti6Al4V alloy: Microstructural and electrochemical characterization," Mater. Chem. Phys., vol. 119, no. 1-2, pp. 337-346, 2010.

[17] C. A. R. Maestro, A. H. S. Bueno, and A. M. de Sousa Malafaia, "Cyclic thermal oxidation evaluation to improve Ti6Al4V surface in applications as biomaterial," J. Mater. Eng. Perform., vol. 28, no. 8, pp. 4991-4997, 2019.

[18] S. Wang, Y. Liu, C. Zhang, Z. Liao, and W. Liu, "The improvement of wettability, biotribological behavior and corrosion resistance of titanium alloy pretreated by thermal oxidation," Tribol. Int., vol. 79, pp. 174182, 2014.

[19] M. T. Mohammed, "Development of surface structure and characteristics of thermally oxidized $\beta$ Ti alloy for biomedical applications," Mater. Res. Express, vol. 6, no. 10, p. 106589, 2019.

[20] M. Wen, C. Wen, P. Hodgson, and Y. Li, "Improvement of the biomedical properties of titanium using SMAT and thermal oxidation," Colloids Surfaces B Biointerfaces, vol. 116, pp. 658-665, 2014.

[21] M. C. García-Alonso et al., "In vitro corrosion behaviour and osteoblast response of thermally 
oxidised Ti6Al4V alloy," Biomaterials, vol. 24, no. 1, pp. 19-26, 2003.

[22] L. Saldaña et al., "Concentration-dependent effects of titanium and aluminium ions released from thermally oxidized Ti6Al4V alloy on human osteoblasts," J. Biomed. Mater. Res. - Part A, vol. 77, no. 2, pp. 220-229, 2006.

[23] P. Kasemanankul, N. Witit-Anun, S. Chaiyakun, and P. Limsuwan, "Apatite formation on rutile $\mathrm{TiO}_{2}$ film deposited using dual cathode DC unbalanced Magnetron sputtering," Eng. J. vol. 16, pp. 37-44, 2012.

[24] S. L. M. Ribeiro Filho, C. H. Lauro, A. H. S. Bueno, and L. C. Brandão, "Influence cutting parameters on the surface quality and corrosion behavior of Ti-6Al$4 \mathrm{~V}$ alloy in synthetic body environment (SBF) using Response Surface Method," Meas. J. Int. Meas. Confed., vol. 88, pp. 223-237, 2016.

[25] T. Kokubo and H. Takadama, "How useful is SBF in predicting in vivo bone bioactivity?," Biomaterials, vol. 27, no. 15, pp. 2907-2915, May 2006.

[26] A. Bloyce, P. Y. Qi, H. Dong, and T. Bell, "Surface modification of titanium alloys for combined improvements in corrosion and wear resistance," Surf. Coatings Technol., vol. 107, no. 2-3, pp. 125-132, 1998.

[27] K. M. Speck and A. C. Fraker, "Anodic polarization behavior of Ti-Ni and Ti-6A 1-4 V in simulated physiological solutions," J. Dent. Res., vol. 59, no. 10, pp. 1590-1595, 1980.

[28] S. Wang, Z. Liao, Y. Liu, and W. Liu, "Influence of thermal oxidation temperature on the microstructural and tribological behavior of Ti6Al4V alloy," Surf. Coatings Technol., vol. 240, pp. 470-477, 2014.

[29] A. Verma, A. Basu, A. K. Bakhshi, and S. A. Agnihotry, "Structural, optical and electrochemical properties of sol-gel derived TiO2 films: Annealing effects," Solid State Ionics, vol. 176, no. 29-30, pp. 2285-2295, 2005.

[30] R. L. Williams, S. A. Brown, and K. Merritt, "Electrochemical studies on the influence of proteins on the corrosion of implant alloys," Biomaterials, vol. 9, no. 2, pp. 181-186, 1988.

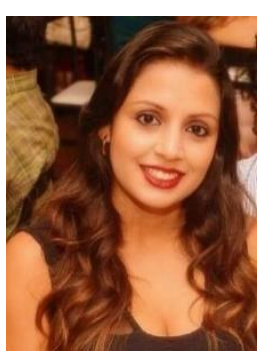

Carolina Aurélia Ribeiro Maestro was born in Congonhas, MG, Brazil in 1992. She received the B.S. in 2019 and started M.S. in Mechanical Engineering in 2020 at Federal University of São João Del Rei. During his undergraduation she performed an internship at SIMaP group from Université Grenoble Alpes (France) in 2018.

From 2016 to 2018, she was involved in studies related to the use of thermal oxidation to improve biomaterial properties of titanium alloy, publishing one article. During internship she studied high temperature oxidation/creep relation in stainless steel. Her research interests now, besides biomaterials, include mechanical loading and corrosion processes related to hydrogen permeation and embrittlement in steels used at oil and gas industries.

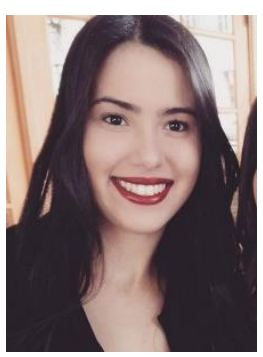

Marina Cristina Ferreira was born in São João Del Rei, MG, Brazil in 1993. She received the B.S. in 2017 and is now is working as maintenance coordinator in a alcohol industry, since 2018. She started a master of business administration in industrial maintenance in 2019 at Senai Faculty.

From 2016 to 2017, she was involved in studies related to the use of thermal oxidation to improve biomaterial properties of titanium alloy, after machining process. This research was the basis for the present paper.

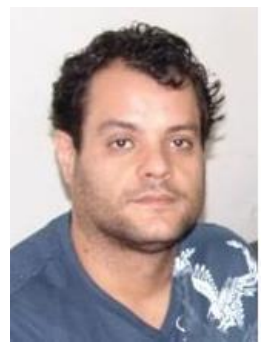

Alysson Helton Santos Bueno was born in Brazil in 1976. He received the B.S. in Industrial Mechanical Engineering in 1999 from Federal University of São João Del Rei and M.S. and the D.Sc. degrees in metallurgical and materials engineering from the Federal University of Rio de Janeiro, in 2003 and 2007, respectively. During the period of 2014/2015 he performed a post-doc at Leeds University (England).

From 2006 to 2008, he was lecturer in Federal University of Rio de Janeiro and since 2009, he has been a Researcher and Professor with the Mechanical Engineering Department, Federal University of São João Del Rei. He is the author of 18 articles. Her research interests include corrosion of metallic materials and concrete, focusing in oil and gas industry, but also publishing studies related to biomaterials and soil corrosion. The researches under development including the effects of temperature, pressure, $\mathrm{CO}_{2}$, $\mathrm{H}_{2} \mathrm{~S}$ and also mechanical loading on the corrosion resistance of steels employed in pipelines used for oil and gas transport. 
Dr. Bueno act also as reviewer for high impact journals as Materials Science and Engineering and received award regarding the third best article of Intercorr Congress.

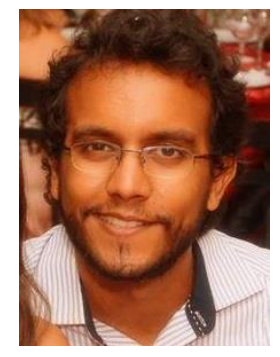

Artur Mariano de Sousa Malafaia was born in São Paulo, SP, Brazil in 1983. He received the B.S. in Mechanical Engineering and M.S. and the D.Sc. degrees in materials science and engineering from the São Paulo University, in 2006, 2009 and 2013, respectively. During his doctorate he stayed one year in Polytechnic University of Catalunya (Spain) and in 2018 performed a post-doc at SIMaP group from Université Grenoble Alpes (France)

From 2010 to 2013, he was lecturer in public and private Universities and since 2013, he has been a Researcher and Professor with the Mechanical Engineering Department, Federal University of São João Del Rei. He is the author of 16 articles. Her research interests include high-temperature oxidation in metallic alloys, concerning isothermal and cyclic tests to evaluate the performance of superalloys, stainless steels, high entropy alloys and $\mathrm{FeMnSiCrNi}$ shape memory alloys. Furthermore, the studies regarding titanium oxidation are focusing in the protective film of rutile used to biomaterial applications.

Dr. de Sousa Malafaia act also as reviewer for high impact journals as Corrosion Science, Materials Letters and Materials \& Design, achieving recognition of "outstanding reviewer status" in Corrosion Science. 